\title{
BMJ Open Healthcare-seeking behaviour in rural Ethiopia: evidence from clinical vignettes
}

\author{
Anagaw D Mebratie, ${ }^{1}$ Ellen Van de Poel, ${ }^{2}$ Zelalem Yilma, ${ }^{1}$ Degnet Abebaw, ${ }^{3}$ \\ Getnet Alemu, ${ }^{4}$ Arjun S Bedi ${ }^{1,5}$
}

To cite: Mebratie AD, Van de Poel E, Yilma Z, et al. Healthcare-seeking behaviour in rural Ethiopia: evidence from clinical vignettes. BMJ Open 2014;4:e004020. doi:10.1136/bmjopen-2013004020

- Prepublication history and additional material for this paper is available online. To view these files please visit the journal online (http://dx.doi.org/10.1136/ bmjopen-2013-004020).

Received 13 September 2013 Revised 5 December 2013 Accepted 10 January 2014
CrossMark

For numbered affiliations see end of article.

Correspondence to Anagaw D Mebratie; mebratie@iss.nl

\section{ABSTRACT}

Objectives: To investigate the determinants of healthcare-seeking behaviour using five contextrelevant clinical vignettes. The analysis deals with three issues: whether and where to seek modern care and when to seek care.

Setting: This study is set in 96 villages located in four main regions of Ethiopia. The participants of this study are 1632 rural households comprising 9455 individuals.

Primary and secondary outcome measures:

Probability of seeking modern care for symptoms related to acute respiratory infections/pneumonia, diarrhoea, malaria, tetanus and tuberculosis.

Conditional on choosing modern healthcare, where to seek care (health post, health centre, clinic and hospital). Conditional on choosing modern healthcare, when to seek care (seek care immediately, the next day, after 2 days, between 3 days to 1 week, a week or more).

Results: We find almost universal preference for modern care. Foregone care ranges from $0.6 \%$ for diarrhoea to $2.5 \%$ for tetanus. There is a systematic relationship between socioeconomic status and choice of providers mainly for adult-related conditions with households in higher consumption quintiles more likely to seek care in health centres, private/Non-Government Organization (NGO) clinics as opposed to health posts. Delays in care-seeking behaviour are apparent mainly for adult-related conditions and among poorer households.

Conclusions: The analysis suggests that the lack of healthcare utilisation is not driven by the inability to recognise health problems or due to a low perceived need for modern care.

\section{INTRODUCTION}

Over the past decade, Ethiopia has recorded notable progress in a number of population health outcomes. These changes have been accompanied by a rapid expansion of healthcare infrastructure at all levels. ${ }^{1-3}$ There has been an 18-fold increase in the number of health posts in 2011 and a 7-fold increase in the number of health centres over the same

\section{Strengths and limitations of this study}

- This paper identifies factors that drive healthcareseeking behaviour in rural Ethiopia using context-specific clinical vignettes which avoid reporting bias in a self-perceived need.

- It examines healthcare-seeking behaviour for child-related and adult-related conditions separately and investigates differences in the level and timing of care sought.

- While the use of clinical vignettes allows us to establish patterns of healthcare-seeking behaviour across population groups that are not driven by differences in health status, there is the risk that the reported hypothetical healthcare-seeking behaviour does not match the actual healthcareseeking behaviour.

- Because the symptoms described in the vignettes are quite specific and severe, they might not pick up foregone care in relation to diseases that are more difficult to recognise or more chronic in nature.

- While we have detailed information on individual and household (demand side) characteristics, we do not have information on healthcare supply, apart from the distance to healthcare facilities, which can be linked to the household data.

period. $^{4-6}$ Consequently, it is estimated that primary healthcare coverage, defined as a village-level access to a health post, has increased from $51 \%$ in 2000 to $92 \%$ in $2011 . .^{3}$

Despite these increases in the supply of healthcare and increases in the utilisation of some specific services, overall outpatient healthcare utilisation rates remain low and have increased only marginally from 0.27 visits in 2000 to 0.3 visits in $2011 .^{13} 7$ Institutional deliveries have gone up from $5 \%$ to $11 \%$ in the same period, but remain extremely low compared with other sub-Saharan African countries (eg, $28.3 \%$ in Eritrea, $43 \%$ in Kenya, $73 \%$ in Senegal and $75 \%$ in Malawi). Therefore, the main aim of this paper is to examine the extent of foregone care and to 
gain an understanding of the factors that are responsible for driving a wedge between availability and utilisation.

Available attempts at measuring foregone care for developed countries typically rely on explicitly asking survey respondents whether they did not use care when needed. ${ }^{9}{ }^{10}$ For low-income and middle-income countries the evidence is mainly limited to the use and inequity in use of maternity and child (preventive) care. ${ }^{11}$ Self-reported information on foregone care is likely to be biased, in particular in low-income settings where knowledge about medical conditions and the need for care may be limited. ${ }^{12}$ This is illustrated by comparing data from the Ethiopian World Health Survey, which reveals that only $13 \%$ of respondents in the poorest quintile reported an unmet need for medical care, ${ }^{13}$ to data from the 2011 Ethiopian Demographic Health Survey in which $74.4 \%$ of women in the poorest quintile reported not having received any antenatal care during their last pregnancy. ${ }^{14}$ The current study therefore uses a series of context-specific child-related and adult-related clinical vignettes to explore the healthcare-seeking behaviour of rural Ethiopian households. Survey respondents are presented with well-defined medical cases and asked about treatment needed. By fixing the medical condition, variation in responses to the vignettes may be attributed only to individual differences in perceptions of the care needed and not due to varying severity in the ill-health condition. ${ }^{15-19}$ Studies that have used clinical vignettes in high-income countries reveal that in these countries lower socioeconomic (ethnic or education level) groups are more likely to consult a doctor for a given set of symptoms. Therefore, they conclude that inequalities in actual healthcare utilisation may be attributed to barriers in healthcare provision and differences in case management due to ethnic origins and not due to difficulties in understanding the symptoms of the disease or due to a lower perception of the need for care. ${ }^{15-18}$ Despite the potential advantages of using healthcare vignettes as an alternative technique to analyse healthcare-seeking behaviour, this approach has not been widely used in the context of low-income and middle-income countries where presumably variations in the perceived need for healthcare are much greater than in high-income countries. ${ }^{11}$ A recent exception is a study in Peru. Based on a vignette designed to capture acute coronary syndrome (ACS), this study reports that women are less likely to recognise symptoms of ACS and also less likely to seek healthcare for chest pain as compared with men. ${ }^{19}$

The analysis deals with three issues. First, do households seek modern care? Second, conditional on seeking modern care, where do they seek care? And finally, what is the timing of their care-seeking behaviour?

\section{DATA}

This study is a part of a larger project which aims to evaluate a pilot community-based health insurance scheme (CBHI) which was rolled out in four main regions (Tigray, Amhara, Oromiya and Southern Nations, Nationalities and People's Region (SNNPR)) of the country in June 2011 (see figure 1). In each of the pilot regions, which together account for about $86 \%$ of the country's population, ${ }^{20}$ the government chose three rural districts as CBHI pilot districts. Districts were selected if they had undertaken healthcare financing reforms designed to increase cost recovery and retention of locally raised revenues and if they had geographically accessible (located close to a main road) health centres.
Figure 1 Location of the survey regions.

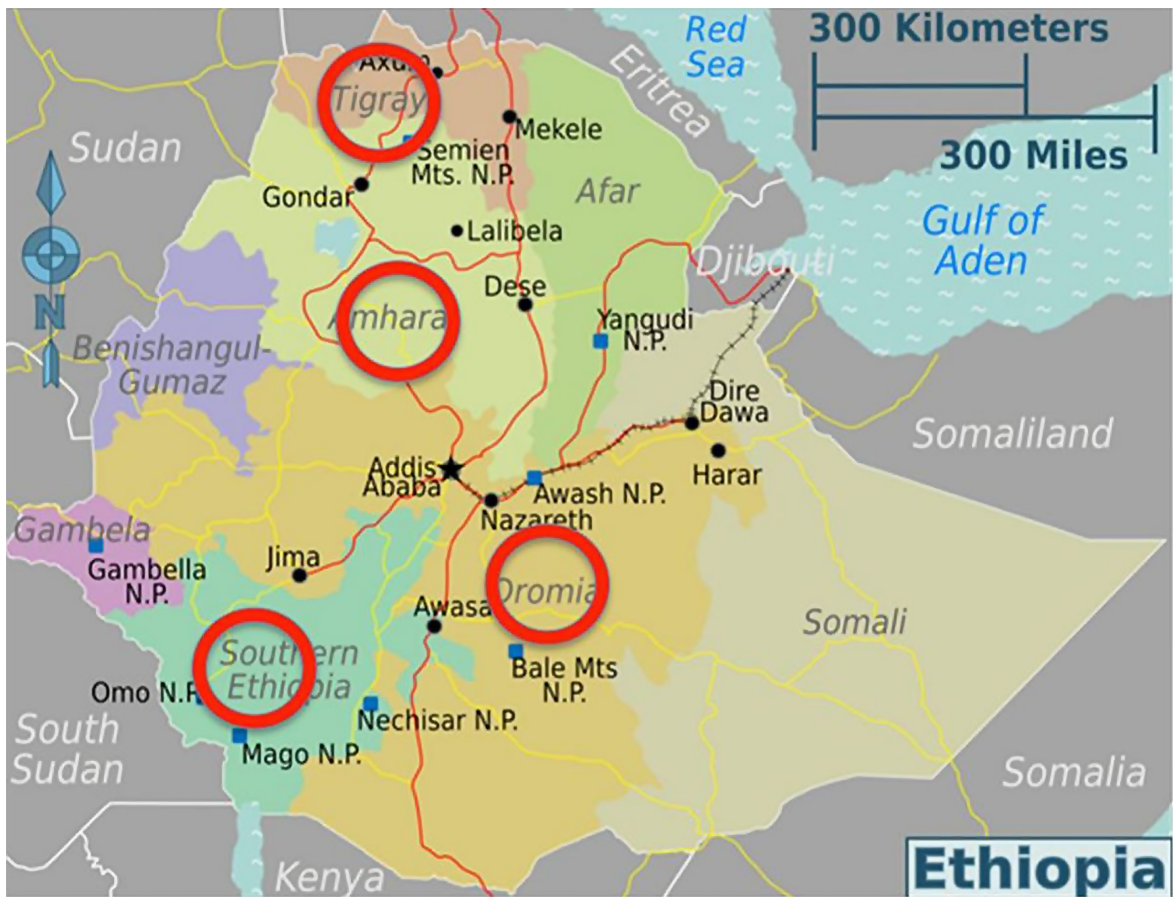


Our household survey covered all $12 \mathrm{CBHI}$ pilot districts and four control districts (1 from each region) which were selected on the same basis as the pilot CBHI districts. It is important to point out that districts were not selected on the basis of healthcare-seeking behaviour or awareness of health issues. From each of the sampled districts, six villages (kebeles) were randomly selected, and from each village 17 households were randomly chosen (based on household lists obtained from the village administrative office), yielding a total of 1632 households comprising 9455 individuals. Respondents were typically the head of the household $(87 \%)$ or the spouse of the household head (13\%). The survey was canvassed between March and April 2011 and contains extensive information on a variety of individual and household socioeconomic attributes including information on health status, healthcare utilisation and healthcareseeking behaviour.

The household survey instrument contains five short clinical vignettes which were developed with input from researchers at Addis Ababa University's School of Public Health. The vignettes are based on illnesses that are widely prevalent in the study region and may be related to acute respiratory infection/pneumonia among babies, diarrhoea affecting female infants, an adult male experiencing malaria, an adult male experiencing tetanus and an adult female affected by tuberculosis. According to information from the WHO's Global Health Observatory, in terms of burden of disease (BOD), diarrhoea, respiratory infections, malaria and unintentional injuries are the four most prominent contributors to the country's BOD. ${ }^{21}$ The vignettes were primarily designed to enable an exploration of heterogeneity in healthcareseeking behaviour for conditions affecting children and adults. For each case, respondents were asked what they would do, that is, whether and where they would seek care and when they would seek care in case they or someone in their household were to experience the symptoms described in the vignettes. Respondents were offered a set of 11 choices for a healthcare provider including an option for foregone care (do nothing). Based on the government's service guidelines, diagnosis and treatment for diarrhoea and malaria are expected to be available at health posts. Health centres and hospitals are expected to be able to cater to all the illnesses described in the vignettes. The vignettes were designed with the view that medically the immediate care-seeking option may be considered the appropriate course of action (for details, see appendix 1).

In addition to the vignettes, information on a range of other variables was collected in order to enable an exploration of the associations between healthcareseeking behaviour and other attributes of interest. These include information on household demographic composition, education of the household head, household health status, economic status as captured by per capita household consumption, attitudes towards modern healthcare and a range of variables to control for access to public (health) infrastructure and finally a set of indicators to control for regional differences. Descriptive statistics for the sample as a whole as well as region-specific descriptive statistics are provided in appendix 2.

\section{METHODS}

The analysis deals with responses to three issues, that is, whether and where to seek care and when to seek care. Whether to seek care-the probability of seeking (modern) care versus the alternative of other care options (do nothing, traditional healers, religious healers and visiting a pharmacy/drug store) is treated as a binary outcome. ORs based on logit regressions of the binary outcome as a function of a number of household and village characteristics are provided for each vignette. This is followed by estimates of a series of multinomial logit (MNL) models for the type of provider sought in response to each vignette. To enhance the tractability of the empirical work, the 11 options are classified into five parts which include seeking care from health posts, health centres, private/NGO clinics, public/private/ NGO hospitals and other options. We follow this fivepart classification for all the vignettes except for the tuberculosis-related vignette where, due to the unlikelihood of getting treatment from a health post for the described symptoms, we classify seeking care from a health post as part of other care options. Conditional on choosing modern care, we examine the timing of careseeking behaviour using a set of ordered logit models. The outcome variable consists of five options-seek care immediately, the next day, after 2 days, between 3 days and 1 week, a week or more.

\section{RESULTS}

\section{Whether to seek care}

Table 1 provides vignette-specific information on the reported choices. The table reveals a striking pattern-a very small proportion of respondents would forego treatment all together (do nothing) with foregone care ranging from $0.6 \%$ for diarrhoea to $2.5 \%$ for tetanus. Similarly, across all vignettes, there is a strong preference for modern care (health centre and health post). This finding is buttressed by the descriptive statistics provided in appendix 2 which show that across the board $85 \%$ of the sample respondents agree with the statement that modern sources of healthcare can be trusted.

To explore patterns in healthcare-seeking behaviour across various characteristics, we provide estimates of the probability of using modern versus alternative care based on a set of logit models. Table 2 presents estimates for each of the vignettes. Across all socioeconomic categories, as captured by the education of the household head and consumption quintiles, healthcare-seeking behaviour for the two most common sources of child morbidity and mortality (acute respiratory infections (ARI) / pneumonia and diarrhoea) does not differ systematically. Differences are more pronounced for 


\section{Table 1 Responses to the vignettes}

\begin{tabular}{|c|c|c|c|c|c|}
\hline & \multicolumn{5}{|l|}{ Case vignette ${ }^{\star}$} \\
\hline & ARI/pneumonia & Diarrhoea & Malaria & Tetanus & Tuberculosis \\
\hline \multicolumn{6}{|l|}{ Where to seek care } \\
\hline Health centre & 50.00 & 56.63 & 62.02 & 59.05 & 60.57 \\
\hline Private clinic & 4.05 & 5.64 & 6.63 & 6.63 & 5.96 \\
\hline Mission/NGO clinic & 0.25 & 0.18 & 0.31 & 0.18 & 0.37 \\
\hline Mission/NGO hospital & 0.06 & 0.06 & 0.18 & 0.06 & 0.00 \\
\hline Pharmacy/drug store & 0.25 & 0.37 & 0.25 & 0.37 & 0.00 \\
\hline Religious healer & 0.74 & 0.31 & 1.10 & 0.12 & 1.11 \\
\hline Traditional healer & 0.80 & 1.04 & 1.84 & 1.78 & 0.68 \\
\hline Do nothing & 1.17 & 0.55 & 1.47 & 2.46 & 1.04 \\
\hline After 2 days & 6.95 & 11.61 & 22.72 & 17.27 & 17.64 \\
\hline Between 3 days and a week & 1.33 & 2.64 & 12.42 & 11.86 & 12.77 \\
\hline After a week or more than a week & 0.44 & 0.88 & 5.73 & 10.05 & 23.20 \\
\hline $\mathrm{N}$ & 1582 & 1593 & 1554 & 1552 & 1582 \\
\hline
\end{tabular}

vignettes related to malaria and TB. The effects of education are mixed, but the effects of economic status point to important inequities. In the case of malaria, households in the richer quintiles are 2.1 (95\% CI 0.89 to $5.08, \mathrm{p}=0.09)$ to 3.4 times $(95 \% \mathrm{CI} 1.37$ to 8.35 , $\mathrm{p}=0.01$ ) more likely to seek modern care as compared with those in the poorest quintile, and for tuberculosis, households in the richer quintiles are 2.3 (95\% CI 1.57 to $3.47, \mathrm{p}<0.0001)$ to 3.6 times $(95 \%$ CI 2.26 to 5.83 , $\mathrm{p}<0.0001)$ more likely to avoid the other care option.

Demographics generally do not have a bearing on the health-seeking behaviour. However, the religion of the household head plays a role. In three of the five cases (ARI/pneumonia, malaria and tuberculosis), households headed by orthodox Christians are 2.5 (95\% CI 1.58 to $4.02, \mathrm{p}<0.0001)$ to 3.7 times $(95 \%$ CI 1.51 to $9.05, \mathrm{p}<0.0001)$ more likely to seek modern care as compared with Muslim-headed households. The regional patterns indicate that for diarrhoea, tetanus and tuberculosis, households in Amhara and Oromiya are far more likely to use modern care as compared with their counterparts in SNNPR.

\section{Where to seek care}

Tables 3 and 4 provide MNL estimates of health-seeking behaviour for each of the child-related and adult-related vignettes, respectively. As covariates related to demographics, trust in modern care and household health status were not found to be systematically related to healthcare-seeking behaviour; these are omitted from the tables for the sake of parsimony. Full regression results can be found in the appendix.

Household heads with informal education are 1.6 times $(95 \%$ CI 1.07 to $2.46, \mathrm{p}=0.02)$ more likely to take their children to health centres for ARI/pneumonia (baseline is health posts) which potentially offer a higher quality of care as compared with household heads with no education. Education does not exert much of an influence on care-seeking behaviour for diarrhoea. However, in both cases, there is clearer evidence that richer households are more likely to access hospitals as opposed to health posts.

Household consumption plays an even more important role in influencing the choice of a healthcare provider for adult conditions (table 4). Households in the bottom quintile are far more likely to visit health posts while all other consumption quintiles are more likely to access higher level care. At the same time, there is no evidence that households in the lower-most quintile are being pushed to other care options, except for tuberculosis.

The estimates reveal systematic differences in the choice of healthcare providers across different religions. For child and adult vignettes, Orthodox Christians and Protestants are more likely to choose higher level care (health centres and private clinics) as compared with Muslims. For instance, in the case of ARI/pneumonia (table 3), Orthodox Christians are about three times $(95 \%$ CI 2.05 to $4.16, \mathrm{p}<0.0001)$ more likely to use health centres. 
Table 2 Probability of seeking modern care-OR based on logit specifications

\begin{tabular}{|c|c|c|c|c|c|c|c|c|c|c|}
\hline \multirow[b]{2}{*}{ Variables } & \multicolumn{2}{|l|}{ ARI/pneumonia } & \multicolumn{2}{|l|}{ Diarrhoea } & \multicolumn{2}{|l|}{ Malaria } & \multicolumn{2}{|l|}{ Tetanus } & \multicolumn{2}{|l|}{ Tuberculosis } \\
\hline & $\overline{\text { OR (95\% Cl) }}$ & p Value & $\overline{\mathrm{OR}}(95 \% \mathrm{Cl})$ & p Value & $\overline{\mathrm{OR}(95 \% \mathrm{Cl})}$ & p Value & $\overline{\mathrm{OR}(95 \% \mathrm{CI})}$ & p Value & $\overline{\mathrm{OR}(95 \% \mathrm{Cl})}$ & p Value \\
\hline \multicolumn{11}{|l|}{ Head sex } \\
\hline Female & 1.0 & & 1.0 & & 1.0 & & 1.0 & & 1.0 & \\
\hline Male & 1.81 (0.67 to 4.85$)$ & 0.24 & 1.93 (0.58 to 6.45$)$ & 0.29 & $1.1(0.48$ to 2.54$)$ & 0.82 & 0.98 (0.43 to 2.24$)$ & 0.97 & $1.3(0.85$ to 1.99$)$ & 0.23 \\
\hline Head age & 1 (0.97 to 1.03$)$ & 0.95 & 0.98 (0.94 to 1.02$)$ & 0.25 & $1.02(0.99$ to 1.05$)$ & 0.17 & $0.98(0.96$ to 1.01$)$ & 0.18 & $0.98(0.97$ to 1$)$ & 0.02 \\
\hline \multicolumn{11}{|l|}{ Head's education } \\
\hline No education at all & 1.0 & & 1.0 & & 1.0 & & 1.0 & & 1.0 & \\
\hline Informal education & 0.75 (0.25 to 2.21$)$ & 0.60 & 0.3 (0.09 to 0.97$)$ & 0.05 & 0.38 (0.19 to 0.77$)$ & 0.01 & 1.32 (0.51 to 3.42$)$ & 0.57 & 1.01 (0.61 to 1.69$)$ & 0.96 \\
\hline Primary and higher & 0.96 (0.45 to 2.04$)$ & 0.91 & 0.87 (0.34 to 2.24$)$ & 0.77 & 1.99 (1 to 3.94$)$ & 0.05 & 1.35 (0.71 to 2.56$)$ & 0.36 & 0.62 (0.44 to 0.87$)$ & 0.01 \\
\hline \multicolumn{11}{|l|}{ Religion of the head } \\
\hline Muslim and other religions & 1.0 & & 1.0 & & 1.0 & & 1.0 & & 1.0 & \\
\hline Orthodox Christian & 2.61 (0.91 to 7.53$)$ & 0.08 & 1.21 (0.33 to 4.38$)$ & 0.78 & $3.7(1.51$ to 9.05$)$ & 0.00 & 2.19 (0.93 to 5.17$)$ & 0.07 & 2.52 (1.58 to 4.02$)$ & 0.00 \\
\hline Protestant & 1.35 (0.47 to 3.93$)$ & 0.58 & 2.34 (0.7 to 7.85$)$ & 0.17 & 1.07 (0.38 to 2.98$)$ & 0.90 & $1.28(0.49$ to 3.3$)$ & 0.61 & $1.72(1.01$ to 2.94$)$ & 0.05 \\
\hline Household size & 1.04 (0.84 to 1.28$)$ & 0.72 & 1.1 (0.85 to 1.43$)$ & 0.45 & 0.9 (0.77 to 1.06$)$ & 0.20 & $1.23(1.02$ to 1.48$)$ & 0.03 & 1.03 (0.95 to 1.12$)$ & 0.48 \\
\hline \multicolumn{11}{|l|}{ HH composition } \\
\hline Proportion of male adults aged $16-64$ & 1.0 & & 1.0 & & 1.0 & & 1.0 & & 1.0 & \\
\hline Proportion of children aged under 6 & 0.08 (0 to 1.53$)$ & 0.09 & 0.04 (0 to 1.12$)$ & 0.06 & 0.23 (0.02 to 2.45$)$ & 0.22 & 0.04 (0 to 0.36$)$ & 0.01 & $0.6(0.18$ to 1.99$)$ & 0.41 \\
\hline Proportion of males aged $6-15$ & $0.86(0.05$ to 15.75$)$ & 0.92 & 0.26 (0.01 to 6.38$)$ & 0.41 & 0.41 (0.04 to 3.93$)$ & 0.44 & $0.16(0.02$ to 1.43$)$ & 0.10 & $1.39(0.44$ to 4.4$)$ & 0.58 \\
\hline Proportion of females aged $6-15$ & $0.03(0$ to 0.53$)$ & 0.02 & 1.09 (0.03 to 37.62$)$ & 0.96 & 0.89 (0.08 to 9.73$)$ & 0.92 & $0.45(0.04$ to 4.65$)$ & 0.50 & $1.11(0.34$ to 3.66$)$ & 0.87 \\
\hline Proportion of females aged 16-64 & $1.5(0.04$ to 50.24$)$ & 0.82 & $1.12(0.02$ to 66.43$)$ & 0.96 & $0.11(0.01$ to 1.49$)$ & 0.10 & $1.82(0.12$ to 28.57$)$ & 0.67 & $0.42(0.13$ to 1.4$)$ & 0.16 \\
\hline Proportion of elderly aged above 64 & $0.14(0.01$ to 3.43$)$ & 0.23 & $0.14(0$ to 4.55$)$ & 0.27 & 0.03 (0 to 0.32$)$ & 0.00 & $0.58(0.05$ to 6.95$)$ & 0.67 & $0.65(0.17$ to 2.46$)$ & 0.52 \\
\hline \multicolumn{11}{|l|}{$\mathrm{HH}$ health status } \\
\hline Proportion of households with good SAH & 1.0 & & 1.0 & & 1.0 & & 1.0 & & 1.0 & \\
\hline Proportion. of household with fair and low SAH & 2.58 (0.71 to 9.33$)$ & 0.15 & $2.17(0.48$ to 9.76$)$ & 0.31 & $2.26(0.8$ to 6.38$)$ & 0.12 & $2.09(0.81$ to 5.39$)$ & 0.13 & $1.04(0.69$ to 1.57$)$ & 0.86 \\
\hline \multicolumn{11}{|c|}{ Consumption quintiles } \\
\hline Poorest quintile & 1.0 & & 1.0 & & 1.0 & & 1.0 & & 1.0 & \\
\hline 2nd quintile & 3.01 (0.95 to 9.58$)$ & 0.06 & 2.93 (0.86 to 9.93$)$ & 0.09 & 2.15 (1.02 to 4.52$)$ & 0.04 & $1.48(0.68$ to 3.24$)$ & 0.33 & 2.34 (1.57 to 3.47$)$ & 0.00 \\
\hline 3rd quintile & 1.66 (0.59 to 4.68$)$ & 0.34 & $1.5(0.5$ to 4.51$)$ & 0.47 & 1.85 (0.84 to 4.09$)$ & 0.13 & 1 (0.46 to 2.18$)$ & 0.99 & 2.27 (1.49 to 3.46$)$ & 0.00 \\
\hline 4th quintile & 0.84 (0.34 to 2.09$)$ & 0.71 & $1.27(0.4$ to 4.08$)$ & 0.68 & 3.38 (1.37 to 8.35$)$ & 0.01 & 1.28 (0.55 to 2.97$)$ & 0.56 & 3.63 (2.26 to 5.83$)$ & 0.00 \\
\hline Richest quintile & 0.8 (0.3 to 2.12$)$ & 0.65 & $3.33(0.78$ to 14.33$)$ & 0.11 & 2.13 (0.89 to 5.08$)$ & 0.09 & 1 (0.42 to 2.38$)$ & 1.00 & 2.53 (1.55 to 4.12$)$ & 0.00 \\
\hline \multicolumn{11}{|l|}{ Trust in modern heathcare } \\
\hline Disagree & 1.0 & & 1.0 & & 1.0 & & 1.0 & & 1.0 & \\
\hline Agree & 1.3 (0.5 to 3.42$)$ & 0.59 & 2.08 (0.71 to 6.15$)$ & 0.18 & 3.59 (1.79 to 7.24$)$ & 0.00 & 2.47 (1.19 to 5.15$)$ & 0.02 & 0.45 (0.27 to 0.76$)$ & 0.00 \\
\hline Neither agree nor disagree & $0.63(0.18$ to 2.19$)$ & 0.47 & $0.63(0.17$ to 2.35$)$ & 0.49 & $0.66(0.28$ to 1.55$)$ & 0.34 & $0.37(0.15$ to 0.88$)$ & 0.03 & $0.2(0.1$ to 0.39$)$ & 0.00 \\
\hline \multicolumn{11}{|l|}{ Access to public infrastructure } \\
\hline \multicolumn{11}{|l|}{ Water using from public sources } \\
\hline No & 1.0 & & 1.0 & & 1.0 & & 1.0 & & 1.0 & \\
\hline Yes & $0.92(0.48$ to 1.76$)$ & 0.80 & $0.86(0.39$ to 1.9$)$ & 0.70 & 1.28 (0.75 to 2.18$)$ & 0.37 & 1.05 (0.61 to 1.8$)$ & 0.87 & $0.97(0.72$ to 1.31$)$ & 0.86 \\
\hline
\end{tabular}


Table 2 Continued

\begin{tabular}{|c|c|c|c|c|c|c|c|c|c|c|}
\hline \multirow[b]{2}{*}{ Variables } & \multicolumn{2}{|l|}{ ARI/pneumonia } & \multicolumn{2}{|l|}{ Diarrhoea } & \multicolumn{2}{|l|}{ Malaria } & \multicolumn{2}{|l|}{ Tetanus } & \multicolumn{2}{|l|}{ Tuberculosis } \\
\hline & OR (95\% Cl) & $p$ Value & $\overline{\mathrm{OR}(95 \% \mathrm{Cl})}$ & $\overline{p \text { Value }}$ & $\overline{\mathrm{OR}(95 \% \mathrm{Cl})}$ & $\overline{p \text { Value }}$ & OR (95\% Cl) & $p$ Value & $\overline{\mathrm{OR}(95 \% \mathrm{Cl})}$ & p Value \\
\hline \multicolumn{11}{|l|}{ Use electricity } \\
\hline No & 1.0 & & 1.0 & & 1.0 & & 1.0 & & 1.0 & \\
\hline Yes & $4.33(0.54$ to 34.81$)$ & 0.17 & $2.22(0.26$ to 18.7$)$ & 0.46 & $0.93(0.32$ to 2.71$)$ & 0.90 & 1.27 (0.4 to 3.98$)$ & 0.69 & 2.58 (1.3 to 5.11$)$ & 0.01 \\
\hline \multicolumn{11}{|l|}{ Access to TV signal } \\
\hline Yes & 1.0 & & 1.0 & & 1.0 & & 1.0 & & 1.0 & \\
\hline No & 1.26 (0.6 to 2.62$)$ & 0.54 & 2.61 (1.07 to 6.35$)$ & 0.04 & 1.16 (0.64 to 2.09$)$ & 0.63 & 0.81 (0.44 to 1.49$)$ & 0.50 & 0.68 (0.48 to 0.97$)$ & 0.03 \\
\hline \multicolumn{11}{|l|}{ Access to mobile signal } \\
\hline Yes & 1.0 & & 1.0 & & 1.0 & & 1.0 & & 1.0 & \\
\hline No & $1.03(0.45$ to 2.36$)$ & 0.95 & $0.92(0.34$ to 2.51$)$ & 0.87 & 1.21 (0.63 to 2.32$)$ & 0.56 & $1.3(0.65$ to 2.6$)$ & 0.46 & 1.02 (0.68 to 1.53$)$ & 0.92 \\
\hline $\begin{array}{l}\text { Travel time to the nearest } \\
\text { health post (in minutes) }\end{array}$ & $1(0.99$ to 1.02$)$ & 0.73 & $0.99(0.97$ to 1.01$)$ & 0.34 & $1.02(1$ to 1.03$)$ & 0.03 & 1.01 (0.99 to 1.02$)$ & 0.21 & 1.01 (1 to 1.01 ) & 0.13 \\
\hline $\begin{array}{l}\text { Travel time to the nearest } \\
\text { health centre (in minutes) }\end{array}$ & $1(0.99$ to 1.01$)$ & 0.47 & 1.01 ( 1 to 1.02$)$ & 0.16 & 0.99 (0.99 to 1$)$ & 0.12 & $1(0.99$ to 1$)$ & 0.23 & 0.99 (0.99 to 1$)$ & 0.00 \\
\hline $\begin{array}{l}\text { Travel time to the nearest } \\
\text { public hospital (in minutes) }\end{array}$ & 0.99 (0.99 to 1$)$ & 0.02 & 0.99 (0.99 to 1$)$ & 0.01 & 0.99 (0.99 to 1$)$ & 0.03 & $1(0.99$ to 1$)$ & 0.16 & 1 (1 to 1$)$ & 0.05 \\
\hline \multicolumn{11}{|l|}{ Regions } \\
\hline SNNPR & 1.0 & & 1.0 & & 1.0 & & 1.0 & & 1.0 & \\
\hline Tigray & $3.6(0.73$ to 17.82$)$ & 0.12 & 11.88 (2.17 to 64.97$)$ & 0.00 & $1.42(0.37$ to 5.48$)$ & 0.62 & 3.15 (0.89 to 11.16$)$ & 0.08 & 0.7 (0.38 to 1.28$)$ & 0.25 \\
\hline Amhara & $4.27(1.11$ to 16.38$)$ & 0.03 & 15.41 (3.42 to 69.52$)$ & 0.00 & $1.55(0.52$ to 4.62$)$ & 0.43 & $2.65(0.94$ to 7.49$)$ & 0.07 & $4.95(2.76$ to 8.88$)$ & 0.00 \\
\hline Oromiya & 3.06 (0.91 to 10.33$)$ & 0.07 & 13.16 (2.6 to 66.66$)$ & 0.00 & $2.48(0.79$ to 7.8$)$ & 0.12 & 5.59 (1.85 to 16.9$)$ & 0.00 & 8.46 (4.49 to 15.95$)$ & 0.00 \\
\hline Pseudo $\mathrm{R}^{2}$ & 0.147 & & 0.21 & & 0.178 & & 0.156 & & 0.195 & \\
\hline $\mathrm{N}$ & 1546 & & 1546 & & 1546 & & 1545 & & 1545 & \\
\hline
\end{tabular}


Table 3 Probability of seeking care for ARI/pneumonia and diarrhoea-relative risk ratios, based on multinomial logit specifications

\begin{tabular}{|c|c|c|c|c|c|c|c|c|}
\hline \multirow[b]{3}{*}{ Variables } & \multicolumn{4}{|l|}{ ARI/pneumonia } & \multicolumn{4}{|l|}{ Diarrhoea } \\
\hline & \multicolumn{2}{|l|}{ Health centre } & \multicolumn{2}{|l|}{ Hospital/clinic } & \multicolumn{2}{|l|}{ Health centre } & \multicolumn{2}{|l|}{ Hospital/clinic } \\
\hline & RRR (95\% Cl) & p Value & RRR (95\% Cl) & p Value & RRR (95\% Cl) & $\mathrm{p}$ Value & RRR (95\% Cl) & p Value \\
\hline \multicolumn{9}{|l|}{ Head's education } \\
\hline No education at all & 1.00 & & 1.00 & & 1.00 & & 1.00 & \\
\hline Informal education & 1.62 (1.07 to 2.46$)$ & 0.02 & 0.76 (0.33 to 1.77$)$ & 0.52 & 1.31 (0.85 to 2.01$)$ & 0.23 & 0.44 (0.18 to 1.07$)$ & 0.07 \\
\hline Primary and higher & 1.25 (0.92 to 1.68$)$ & 0.15 & $0.61(0.34$ to 1.1$)$ & 0.10 & 0.89 (0.66 to 1.2$)$ & 0.45 & 0.6 (0.35 to 1.02$)$ & 0.06 \\
\hline \multicolumn{9}{|l|}{ Religion of the head } \\
\hline Muslim and other religions & 1.00 & & 1.00 & & 1.00 & & 1.00 & \\
\hline Orthodox Christian & 2.92 (2.05 to 4.16$)$ & 0.00 & 4.22 (2.25 to 7.9$)$ & 0.00 & 3.06 (2.1 to 4.47$)$ & 0.00 & 3.67 (2.05 to 6.57 ) & 0.00 \\
\hline Protestant & 1.73 (0.99 to 3.02$)$ & 0.06 & $0.6(0.26$ to 1.41$)$ & 0.24 & $1.98(1.14$ to 3.44$)$ & 0.02 & 0.71 (0.3 to 1.65$)$ & 0.42 \\
\hline \multicolumn{9}{|l|}{ Consumption quintiles } \\
\hline Poorest quintile & 1.00 & & 1.00 & & 1.00 & & 1.00 & \\
\hline 2nd quintile & 1.44 (0.98 to 2.12$)$ & 0.06 & 2.43 (1.05 to 5.62$)$ & 0.04 & 1.48 (1.01 to 2.17$)$ & 0.04 & 2.48 (1.17 to 5.24$)$ & 0.02 \\
\hline 3rd quintile & 1.38 (0.93 to 2.05$)$ & 0.11 & $2.63(1.1$ to 6.31$)$ & 0.03 & 1.66 (1.11 to 2.48$)$ & 0.01 & 2.21 (0.99 to 4.95$)$ & 0.05 \\
\hline 4th quintile & $1.42(0.94$ to 2.14$)$ & 0.10 & 2.96 (1.21 to 7.22$)$ & 0.02 & 1.39 (0.92 to 2.1$)$ & 0.12 & 2.73 (1.25 to 5.99$)$ & 0.01 \\
\hline Richest quintile & 1.4 (0.89 to 2.2$)$ & 0.15 & 4.38 (1.75 to 10.97$)$ & 0.00 & 1.46 (0.93 to 2.29$)$ & 0.10 & 2.63 (1.12 to 6.16$)$ & 0.03 \\
\hline \multicolumn{9}{|l|}{ Access to public infrastructure } \\
\hline \multicolumn{9}{|l|}{ Water using from public sources } \\
\hline No & 1.00 & & 1.00 & & 1.00 & & 1.00 & \\
\hline Yes & 1.38 (1.06 to 1.8$)$ & 0.02 & 0.64 (0.38 to 1.09$)$ & 0.10 & $1.11(0.85$ to 1.45$)$ & 0.44 & 0.65 (0.4 to 1.06$)$ & 0.08 \\
\hline \multicolumn{9}{|l|}{ Use electricity } \\
\hline No & 1.00 & & 1.00 & & 1.00 & & 1.00 & \\
\hline Yes & 4.51 (2.41 to 8.47$)$ & 0.00 & $5.2(1.9$ to 14.21$)$ & 0.00 & 3.96 (2.06 to 7.62$)$ & 0.00 & 5.58 (2.13 to 14.62$)$ & 0.00 \\
\hline \multicolumn{9}{|l|}{ Access to TV signal } \\
\hline Yes & 1.00 & & 1.00 & & 1.00 & & 1.00 & \\
\hline No & 0.88 (0.65 to 1.2$)$ & 0.43 & $0.77(0.42$ to 1.42$)$ & 0.41 & 0.76 (0.55 to 1.04$)$ & 0.08 & 0.93 (0.54 to 1.62$)$ & 0.80 \\
\hline \multicolumn{9}{|l|}{ Access to mobile signal } \\
\hline Yes & 1.00 & & 1.00 & & 1.00 & & 1.00 & \\
\hline No & 1.81 (1.28 to 2.56$)$ & 0.00 & $0.85(0.45$ to 1.61$)$ & 0.63 & $0.93(0.65$ to 1.33$)$ & 0.67 & $0.3(0.17$ to 0.52$)$ & 0.00 \\
\hline Travel time to the nearest health post (in minutes) & 1.01 (1.01 to 1.02$)$ & 0.00 & 1 (0.99 to 1.02$)$ & 0.72 & $1.02(1.01$ to 1.02$)$ & 0.00 & 1 (0.99 to 1.02$)$ & 0.78 \\
\hline Travel time to the nearest health centre (in minutes) & 0.99 (0.99 to 0.99$)$ & 0.00 & $1(1$ to 1.01$)$ & 0.53 & $0.99(0.99$ to 1$)$ & 0.00 & 1 (1 to 1.01$)$ & 0.25 \\
\hline Travel time to the nearest public hospital (in minutes) & $1(1$ to 1$)$ & 0.24 & $0.99(0.99$ to 1$)$ & 0.03 & $1(1$ to 1$)$ & 0.56 & 0.99 (0.99 to 1$)$ & 0.00 \\
\hline \multicolumn{9}{|l|}{ Regions } \\
\hline SNNPR & 1.00 & & 1.00 & & 1.00 & & 1.00 & \\
\hline Tigray & $0.39(0.21$ to 0.72$)$ & 0.00 & $0.03(0.01$ to 0.11$)$ & 0.00 & $0.41(0.23$ to 0.76$)$ & 0.00 & $0.04(0.01$ to 0.13$)$ & 0.00 \\
\hline Amhara & 5.64 (3.15 to 10.11$)$ & 0.00 & 0.54 (0.23 to 1.29$)$ & 0.17 & 4.28 (2.4 to 7.63$)$ & 0.00 & $1.08(0.46$ to 2.55$)$ & 0.86 \\
\hline Oromiya & 2.23 (1.26 to 3.97$)$ & 0.01 & 0.28 (0.12 to 0.66$)$ & 0.00 & $3.2(1.8$ to 5.69$)$ & 0.00 & $1.06(0.46$ to 2.44$)$ & 0.90 \\
\hline Pseudo $\mathrm{R}^{2}$ & 0.1758 & 0.1761 & & & & & & \\
\hline $\mathrm{N}$ & 1527 & 1537 & & & & & & \\
\hline
\end{tabular}


Table 4 Probability of seeking care for malaria, tetanus and tuberculosis-relative risk ratios based on multinomial logit specifications

\begin{tabular}{|c|c|c|c|c|c|c|c|c|c|c|}
\hline \multirow[b]{3}{*}{ Variables } & \multicolumn{4}{|l|}{ Malaria } & \multicolumn{4}{|l|}{ Tetanus } & \multirow{2}{*}{\multicolumn{2}{|c|}{$\frac{\text { Tuberculosis }}{\text { Hospital }}$}} \\
\hline & \multicolumn{2}{|l|}{ Health centre } & \multicolumn{2}{|l|}{ Hospital } & \multicolumn{2}{|l|}{ Health centre } & \multicolumn{2}{|l|}{ Hospital } & & \\
\hline & RRR (95\% Cl) & p Value & RRR (95\% Cl) & p Value & RRR (95\% Cl) & p Value & RRR (95\% Cl) & p Value & RRR (95\% Cl) & p Value \\
\hline \multicolumn{11}{|l|}{ Head's education } \\
\hline No education at all & 1.00 & & 1.00 & & 1.00 & & 1.00 & & 1.00 & \\
\hline Informal education & 1.55 (0.88 to 2.73$)$ & 0.13 & 1.55 (0.62 to 3.92$)$ & 0.35 & $1.14(0.71$ to 1.84$)$ & 0.59 & $0.58(0.23$ to 1.5$)$ & 0.27 & 1.26 (0.75 to 2.13$)$ & 0.38 \\
\hline Primary and higher & $0.71(0.5$ to 1$)$ & 0.05 & 0.99 (0.49 to 2.01$)$ & 0.97 & 0.81 (0.58 to 1.14$)$ & 0.23 & $0.7(0.35$ to 1.42$)$ & 0.32 & $0.9(0.56$ to 1.46$)$ & 0.67 \\
\hline \multicolumn{11}{|l|}{ Religion of the head } \\
\hline Muslim and other religions & 1.00 & & 1.00 & & 1.00 & & 1.00 & & 1.00 & \\
\hline Orthodox Christian & 2.45 (1.53 to 3.94$)$ & 0.00 & 0.72 (0.34 to 1.55$)$ & 0.41 & 2.75 (1.77 to 4.27 ) & 0.00 & $0.68(0.32$ to 1.44$)$ & 0.31 & $0.16(0.1$ to 0.27$)$ & 0.00 \\
\hline Protestant & 2.35 (1.29 to 4.26$)$ & 0.01 & 0.35 (0.09 to 1.37$)$ & 0.13 & 1.97 (1.09 to 3.54$)$ & 0.02 & 0.26 (0.06 to 1.09$)$ & 0.07 & $0.14(0.05$ to 0.39$)$ & 0.00 \\
\hline \multicolumn{11}{|l|}{ Consumption quintiles } \\
\hline Poorest quintile & 1.00 & & 1.00 & & 1.00 & & 1.00 & & 1.00 & \\
\hline 2nd quintile & 1.99 (1.32 to 3.01$)$ & 0.00 & $3.36(1.05$ to 10.78$)$ & 0.04 & 1.79 (1.2 to 2.67$)$ & 0.01 & 7.39 (1.47 to 37.25$)$ & 0.02 & 1.81 (0.79 to 4.15$)$ & 0.16 \\
\hline 3rd quintile & $2.23(1.43$ to 3.48$)$ & 0.00 & $4.8(1.52$ to 15.2$)$ & 0.01 & $1.62(1.06$ to 2.49$)$ & 0.03 & $11.48(2.36$ to 55.8$)$ & 0.00 & $2.22(0.97$ to 5.06$)$ & 0.06 \\
\hline 4th quintile & 2.57 (1.59 to 4.17$)$ & 0.00 & $8.62(2.78$ to 26.76$)$ & 0.00 & 2.7 (1.68 to 4.33$)$ & 0.00 & 28.87 (5.99 to 139.06$)$ & 0.00 & $3.47(1.55$ to 7.75$)$ & 0.00 \\
\hline Richest quintile & 1.99 (1.19 to 3.33$)$ & 0.01 & $5.16(1.53$ to 17.37$)$ & 0.01 & $1.82(1.11$ to 2.98$)$ & 0.02 & 9.32 (1.78 to 48.69$)$ & 0.01 & 2.95 (1.26 to 6.91$)$ & 0.01 \\
\hline \multicolumn{11}{|l|}{ Access to public infrastructure } \\
\hline \multicolumn{11}{|l|}{ Water using from public sources } \\
\hline No & 1.00 & & 1.00 & & 1.00 & & 1.00 & & 1.00 & \\
\hline Yes & $1.08(0.79$ to 1.47$)$ & 0.65 & $0.47(0.25$ to 0.89$)$ & 0.02 & $1.02(0.76$ to 1.38$)$ & 0.88 & $0.34(0.18$ to 0.66$)$ & 0.00 & $0.56(0.37$ to 0.84$)$ & 0.01 \\
\hline \multicolumn{11}{|l|}{ Use electricity } \\
\hline No & 1.00 & & 1.00 & & 1.00 & & 1.00 & & 1.00 & \\
\hline Yes & $3.83(1.73$ to 8.5$)$ & 0.00 & 6.23 (1.9 to 20.39$)$ & 0.00 & 2.34 (1.22 to 4.47$)$ & 0.01 & 3.68 (1.09 to 12.42$)$ & 0.04 & $1.43(0.76$ to 2.69$)$ & 0.26 \\
\hline \multicolumn{11}{|l|}{ Access to TV signal } \\
\hline Yes & 1.00 & & 1.00 & & 1.00 & & 1.00 & & 1.00 & \\
\hline No & $0.47(0.32$ to 0.69$)$ & 0.00 & 2.14 (0.99 to 4.61$)$ & 0.05 & 0.59 (0.41 to 0.84$)$ & 0.00 & 2.14 (0.99 to 4.61$)$ & 0.05 & $1.24(0.8$ to 1.94$)$ & 0.34 \\
\hline \multicolumn{11}{|l|}{ Access to mobile signal } \\
\hline Yes & 1.00 & & 1.00 & & 1.00 & & 1.00 & & 1.00 & \\
\hline No & 1.35 (0.87 to 2.09$)$ & 0.17 & $0.44(0.21$ to 0.92$)$ & 0.03 & $1.17(0.78$ to 1.77$)$ & 0.44 & 0.39 (0.19 to 0.83$)$ & 0.01 & 0.76 (0.48 to 1.2$)$ & 0.24 \\
\hline $\begin{array}{l}\text { Travel time to the nearest health } \\
\text { post (in minutes) }\end{array}$ & 1.01 (1 to 1.02$)$ & 0.00 & 1 (0.99 to 1.02$)$ & 0.82 & $1.02(1.01$ to 1.02$)$ & 0.00 & 1 (0.99 to 1.02$)$ & 0.63 & 1 (0.99 to 1.01$)$ & 0.53 \\
\hline $\begin{array}{l}\text { Travel time to the nearest health } \\
\text { centre (in minutes) }\end{array}$ & 0.99 (0.99 to 0.99$)$ & 0.00 & 1 (0.99 to 1.01$)$ & 0.83 & 0.99 (0.99 to 0.99$)$ & 0.00 & $1(0.99$ to 1.01$)$ & 0.68 & 1 (1 to 1.01$)$ & 0.38 \\
\hline $\begin{array}{l}\text { Travel time to the nearest public } \\
\text { hospital (in minutes) }\end{array}$ & 1 (1 to 1.01$)$ & 0.03 & 1 (1 to 1.01$)$ & 0.32 & 1 (1 to 1$)$ & 0.03 & $1(0.99$ to 1$)$ & 0.47 & $1(0.99$ to 1$)$ & 0.17 \\
\hline \multicolumn{11}{|l|}{ Regions } \\
\hline SNNPR & 1.00 & & 1.00 & & 1.00 & & 1.00 & & 1.00 & \\
\hline Tigray & 0.87 (0.45 to 1.67$)$ & 0.68 & $0.57(0.14$ to 2.4$)$ & 0.44 & $0.8(0.43$ to 1.52$)$ & 0.50 & 0.73 (0.18 to 2.96$)$ & 0.66 & 1.26 (0.44 to 3.61$)$ & 0.67 \\
\hline Amhara & 4.98 (2.65 to 9.37$)$ & 0.00 & 3.01 (0.9 to 10.1$)$ & 0.07 & 3.95 (2.17 to 7.21$)$ & 0.00 & $1.55(0.46$ to 5.28$)$ & 0.48 & $0.93(0.38$ to 2.25$)$ & 0.86 \\
\hline Oromiya & 10.47 (5.26 to 20.83 ) & 0.00 & $3.72(1.07$ to 12.97$)$ & 0.04 & 10.56 (5.37 to 20.77$)$ & 0.00 & $4.22(1.23$ to 14.4$)$ & 0.02 & $0.59(0.24$ to 1.47$)$ & 0.26 \\
\hline Pseudo $\mathrm{R}^{2}$ & 0.192 & 0.199 & 0.176 & & & & & & & \\
\hline $\mathrm{N}$ & 1523 & 1507 & 1545 & & & & & & & \\
\hline
\end{tabular}




\section{When to seek care}

Table 1 displays the distribution of the time lag between the onset of symptoms and the action of respondents. For both the child-related vignettes, the reaction of respondents is swift and 91 (85) \% report that they would seek care immediately, that is, on the same day as the occurrence of symptoms or the next day in the case of ARI/pneumonia (diarrhoea). For the other vignettes, the response is slower and ranges from an immediate/ next day response rate of $46 \%$ for tuberculosis to $59 \%$ for malaria and tetanus. For tuberculosis, the reaction time is quite slow with about a quarter of respondents indicating that they would wait for a week or more after the onset of symptoms.

ORs based on a set of vignette-specific ordered logit estimates are provided in tables 5 and 6 . Across the various vignettes, educational attainment seems to play a stronger role in influencing the timing of care as opposed to the choice of a healthcare provider. For instance, in the case of tuberculosis, household heads with informal education are 1.6 (95\% CI 1.12 to 2.18 , $\mathrm{p}=0.01$ ) times more likely to delay seeking immediate care as opposed to those with secondary education. Similarly, for diarrhoea, malaria and tetanus vignettes,

Table 5 When to seek modern care for ARI/pneumonia and diarrhoea-ORs based on ordered logit specifications

\begin{tabular}{|c|c|c|c|c|}
\hline \multirow[b]{2}{*}{ Variables } & \multicolumn{2}{|l|}{ ARI/pneumonia } & \multicolumn{2}{|l|}{ Diarrhoea } \\
\hline & OR (95\% Cl) & p Value & OR (95\% Cl) & p Value \\
\hline \multicolumn{5}{|l|}{ Head's education } \\
\hline No education at all & 1.00 & & 1.00 & \\
\hline Informal education & $0.99(0.7$ to 1.41$)$ & 0.97 & $0.89(0.64$ to 1.24$)$ & 0.49 \\
\hline Primary and higher & $0.78(0.6$ to 1.01$)$ & 0.06 & $0.66(0.51$ to 0.84$)$ & 0.00 \\
\hline \multicolumn{5}{|l|}{ Consumption quintiles } \\
\hline Poorest quintile & 1.00 & & 1.00 & \\
\hline 2nd quintile & $0.94(0.68$ to 1.29$)$ & 0.69 & $0.84(0.61$ to 1.15$)$ & 0.27 \\
\hline 3rd quintile & $0.81(0.57$ to 1.14$)$ & 0.22 & $0.93(0.67$ to 1.3$)$ & 0.67 \\
\hline 4th quintile & 0.65 (0.45 to 0.93$)$ & 0.02 & $0.84(0.59$ to 1.18$)$ & 0.32 \\
\hline Richest quintile & $0.61(0.41$ to 0.91$)$ & 0.02 & $1(0.69$ to 1.45$)$ & 0.99 \\
\hline \multicolumn{5}{|l|}{ Trust in modern healthcare } \\
\hline Disagree & 1.00 & & 1.00 & \\
\hline Agree & 1.47 (0.98 to 2.22$)$ & 0.07 & 1.46 (1 to 2.13$)$ & 0.05 \\
\hline Neither agree nor disagree & $1.7(0.98$ to 2.96$)$ & 0.06 & $1.18(0.7$ to 1.99$)$ & 0.54 \\
\hline \multicolumn{5}{|l|}{ Access to public infrastructure } \\
\hline \multicolumn{5}{|l|}{ Water using from public sources } \\
\hline No & 1.00 & & 1.00 & \\
\hline Yes & $0.76(0.6$ to 0.96$)$ & 0.02 & $1.01(0.81$ to 1.25$)$ & 0.94 \\
\hline \multicolumn{5}{|l|}{ Use electricity } \\
\hline No & 1.00 & & 1.00 & \\
\hline Yes & $0.63(0.38$ to 1.03$)$ & 0.07 & $0.65(0.41$ to 1.01$)$ & 0.06 \\
\hline \multicolumn{5}{|l|}{ Access to TV signal } \\
\hline Yes & 1.00 & & 1.00 & \\
\hline No & $0.72(0.54$ to 0.96$)$ & 0.03 & $0.48(0.37$ to 0.63$)$ & 0.00 \\
\hline \multicolumn{5}{|l|}{ Access to mobile signal } \\
\hline Yes & 1.00 & & 1.00 & \\
\hline No & $1.17(0.86$ to 1.6$)$ & 0.31 & $0.92(0.69$ to 1.22$)$ & 0.56 \\
\hline Travel time to the nearest health post (in minutes) & $0.99(0.99$ to 1$)$ & 0.06 & $0.99(0.99$ to 1$)$ & 0.01 \\
\hline Travel time to the nearest health centre (in minutes) & $1(0.99$ to 1$)$ & 0.02 & $1(1$ to 1$)$ & 0.26 \\
\hline Travel time to the nearest public hospital (in minutes) & 1 (1 to 1.01$)$ & 0.00 & 1 (1 to 1$)$ & 0.35 \\
\hline \multicolumn{5}{|l|}{ Religion of the head } \\
\hline Muslim and other religions & 1.00 & & 1.00 & \\
\hline Orthodox Christian & 1.95 (1.43 to 2.65$)$ & 0.00 & $1.23(0.93$ to 1.63$)$ & 0.15 \\
\hline Protestant & $0.94(0.6$ to 1.49$)$ & 0.81 & $1.05(0.68$ to 1.64$)$ & 0.81 \\
\hline \multicolumn{5}{|l|}{ Regions } \\
\hline SNNPR & 1.00 & & 1.00 & \\
\hline Tigray & $0.29(0.17$ to 0.47$)$ & 0.00 & $0.66(0.41$ to 1.06$)$ & 0.09 \\
\hline Amhara & $0.1(0.06$ to 0.17$)$ & 0.00 & 0.18 (0.11 to 0.28$)$ & 0.00 \\
\hline Oromiya & $0.37(0.23$ to 0.6$)$ & 0.00 & $0.93(0.59$ to 1.45$)$ & 0.74 \\
\hline Pseudo $R^{2}$ & 0.081 & & 0.063 & \\
\hline $\mathrm{N}$ & 1502 & & 1518 & \\
\hline
\end{tabular}


Table 6 When to seek modern care for malaria, tetanus and tuberculosis-ORs based on ordered logit specifications

\begin{tabular}{|c|c|c|c|c|c|c|}
\hline \multirow[b]{2}{*}{ Variables } & \multicolumn{2}{|l|}{ Malaria } & \multicolumn{2}{|l|}{ Tetanus } & \multicolumn{2}{|l|}{ Tuberculosis } \\
\hline & $\overline{\text { OR (95\% Cl) }}$ & p Value & $\overline{\text { OR (95\% Cl) }}$ & p Value & $\overline{\text { OR (95\% Cl) }}$ & $\overline{p \text { Value }}$ \\
\hline \multicolumn{7}{|l|}{ Head's education } \\
\hline No education at all & 1.00 & & 1.00 & & 1.00 & \\
\hline Informal education & $0.94(0.68$ to 1.28$)$ & 0.68 & 0.81 (0.59 to 1.11$)$ & 0.19 & 1.57 (1.12 to 2.18$)$ & 0.01 \\
\hline Primary and higher & $0.66(0.52$ to 0.84$)$ & 0.00 & 0.81 (0.64 to 1.02$)$ & 0.08 & $1(0.77$ to 1.31$)$ & 0.97 \\
\hline \multicolumn{7}{|l|}{ Consumption quintiles } \\
\hline Poorest quintile & 1.00 & & 1.00 & & 1.00 & \\
\hline 2nd quintile & 1.09 (0.8 to 1.47$)$ & 0.59 & $0.99(0.73$ to 1.32$)$ & 0.93 & $0.94(0.66$ to 1.35$)$ & 0.75 \\
\hline 3rd quintile & $0.84(0.61$ to 1.15$)$ & 0.27 & $0.65(0.47$ to 0.88$)$ & 0.01 & 0.91 (0.63 to 1.32$)$ & 0.62 \\
\hline 4th quintile & 0.55 (0.39 to 0.77$)$ & 0.00 & $0.52(0.37$ to 0.71$)$ & 0.00 & $0.83(0.57$ to 1.2$)$ & 0.32 \\
\hline Richest quintile & 0.63 (0.44 to 0.9$)$ & 0.01 & 0.48 (0.34 to 0.68$)$ & 0.00 & $1.02(0.67$ to 1.54$)$ & 0.93 \\
\hline \multicolumn{7}{|l|}{ Trust in modern health care } \\
\hline Disagree & 1.00 & & 1.00 & & 1.00 & \\
\hline Agree & $0.83(0.58$ to 1.18$)$ & 0.30 & $0.82(0.58$ to 1.17$)$ & 0.28 & $1.7(1.16$ to 2.49$)$ & 0.01 \\
\hline Neither agree nor disagree & $0.44(0.27$ to 0.72$)$ & 0.00 & 0.59 (0.36 to 0.98$)$ & 0.04 & $0.8(0.45$ to 1.42$)$ & 0.45 \\
\hline \multicolumn{7}{|l|}{ Access to public infrastructure } \\
\hline \multicolumn{7}{|l|}{ Water using from public sources } \\
\hline No & 1.00 & & 1.00 & & 1.00 & \\
\hline Yes & $0.76(0.62$ to 0.94$)$ & 0.01 & $0.79(0.64$ to 0.98$)$ & 0.03 & $0.92(0.73$ to 1.16$)$ & 0.46 \\
\hline \multicolumn{7}{|l|}{ Use electricity } \\
\hline No & 1.00 & & 1.00 & & 1.00 & \\
\hline Yes & $1.1(0.73$ to 1.66$)$ & 0.64 & $0.67(0.44$ to 1.04$)$ & 0.08 & $0.95(0.62$ to 1.46$)$ & 0.82 \\
\hline \multicolumn{7}{|l|}{ Access to TV signal } \\
\hline Yes & 1.00 & & 1.00 & & 1.00 & \\
\hline No & 0.5 (0.38 to 0.64$)$ & 0.00 & $0.55(0.43$ to 0.71$)$ & 0.00 & $0.46(0.34$ to 0.61$)$ & 0.00 \\
\hline \multicolumn{7}{|l|}{ Access to mobile signal } \\
\hline Yes & 1.00 & & 1.00 & & 1.00 & \\
\hline No & $1.22(0.93$ to 1.6$)$ & 0.15 & 1.21 (0.93 to 1.59$)$ & 0.16 & 2.13 (1.58 to 2.88$)$ & 0.00 \\
\hline $\begin{array}{l}\text { Travel time to the nearest health } \\
\text { post (in minutes) }\end{array}$ & $0.99(0.99$ to 1$)$ & 0.02 & 1.01 (1 to 1.01$)$ & 0.03 & $1(1$ to 1.01$)$ & 0.73 \\
\hline $\begin{array}{l}\text { Travel time to the nearest health } \\
\text { centre (in minutes) }\end{array}$ & $1(1$ to 1$)$ & 0.16 & 1 (1 to 1$)$ & 0.89 & 1 (1 to 1$)$ & 0.91 \\
\hline $\begin{array}{l}\text { Travel time to the nearest public } \\
\text { hospital (in minutes) }\end{array}$ & 1 (1 to 1$)$ & 0.00 & 1 (1 to 1$)$ & 0.01 & $1(1$ to 1.01$)$ & 0.00 \\
\hline \multicolumn{7}{|l|}{ Religion of the head } \\
\hline Muslim and other religions & 1.00 & & 1.00 & & 1.00 & \\
\hline Orthodox Christian & $0.69(0.53$ to 0.91$)$ & 0.01 & $0.64(0.49$ to 0.84$)$ & 0.00 & $0.42(0.32$ to 0.56$)$ & 0.00 \\
\hline Protestant & 0.76 (0.49 to 1.19$)$ & 0.23 & $0.69(0.45$ to 1.07$)$ & 0.09 & $0.64(0.36$ to 1.14$)$ & 0.13 \\
\hline \multicolumn{7}{|l|}{ Regions } \\
\hline SNNPR & 1.00 & & 1.00 & & 1.00 & \\
\hline Tigray & 0.49 (0.31 to 0.78$)$ & 0.00 & 0.45 (0.29 to 0.72$)$ & 0.00 & 0.41 (0.22 to 0.76$)$ & 0.01 \\
\hline Amhara & $0.16(0.1$ to 0.25$)$ & 0.00 & $0.2(0.13$ to 0.31$)$ & 0.00 & $0.12(0.06$ to 0.21$)$ & 0.00 \\
\hline Oromiya & $1.2(0.77$ to 1.87$)$ & 0.42 & $1.02(0.66$ to 1.58$)$ & 0.92 & $0.88(0.49$ to 1.57$)$ & 0.66 \\
\hline Pseudo $\mathrm{R}^{2}$ & 0.064 & & 0.052 & & 0.088 & \\
\hline $\mathrm{N}$ & 1475 & & 1477 & & 1192 & \\
\hline
\end{tabular}

the estimates show that household heads with primary or secondary education are systematically more likely to seek care immediately as opposed to their less educated counterparts. Households in richer quintiles are also more likely to seek care immediately. For instance, in the case of ARI/pneumonia, households in the two highest quintiles are $35(95 \%$ CI 0.45 to $0.93, \mathrm{p}=0.02)$ to $39 \%$ (95\% CI 0.41 to $0.91, \mathrm{p}=0.02$ ) more likely to seek care immediately as compared with households in lower consumption quintiles. Similar patterns prevail for malaria and tetanus, though not for diarrhoea and tuberculosis.

The link between the religion of the household head and the time of healthcare-seeking behaviour varies across vignettes. For the case of child symptoms, Orthodox Christians are more likely to delay care than 
Muslims while the reverse is true for the adult vignettes. The effects of travel time do not show a clear pattern. Regional differences continue to remain pronounced. Almost all the vignette households living in the Amhara and Tigray region display a greater propensity to seek care immediately as compared with households living in SNNPR. Differences are particularly pronounced in the case of the Amahra region where households are at least $80 \%(95 \%$ CI 0.13 to $0.31, \mathrm{p}<0.0001)$ more likely to seek care immediately as opposed to households living in SNNPR (table 6).

\section{DISCUSSION}

Ethiopia has invested substantially in its healthcare infrastructure in the last decade through the expansion of health posts and health centres. ${ }^{4-6}$ Despite these investments, utilisation of maternal and childcare and more general outpatient utilisation rates remain among the lowest in sub-Saharan Africa. ${ }^{7}$ To gain an understanding of the factors responsible for driving a wedge between availability and utilisation, this paper relied on five context-relevant clinical vignettes for common child and adult conditions to probe whether households seek modern care, where they seek care and the timing of care-seeking behaviour.

The estimates suggest that the large majority of respondents recognise the severity of the symptoms described in the vignettes and prefer modern over traditional care and self-treatment. This is surprising given the country's low socioeconomic development and low educational stock. ${ }^{22}$ A potential explanation may lie in the rapid and recent spread of health posts and health extension workers who since 2003 have been charged with the responsibility of raising awareness of health issues. ${ }^{6}$ Indeed, the uniformity of healthcare-seeking behaviour for child morbidity displayed across consumption quintiles suggests that information on health education and the appropriate course of action for the most common childhood diseases, which is the focus of the health extension programme, seems to have percolated to the lowest socioeconomic quintiles.

For adult-related conditions, we do find variations across socioeconomic status with households in the highest consumption quintile two to three times more likely to seek modern care as compared with households in the lowest quintiles. These socioeconomic inequalities are also found in the choice of a healthcare provider and the timing of seeking care. Households in the lowest consumption quintiles are generally more likely to resort to lower level care and postpone seeking care compared with better-off households. Taking the example of tuberculosis, which can only be properly treated in health centres and hospitals, we find that households in the upper consumption quintile are three times more likely to seek care in a hospital compared with those in the lower consumption quintile. We also find variations in the timing of care-seeking behaviour with respondents typically acting faster for child-related conditions as compared with adult conditions.

There are differences in healthcare-seeking behaviour across religion. Orthodox Christian households are more likely to seek modern care, to seek higher level modern care and seek care earlier (for adult conditions) as compared with Muslim-headed households. While the reasons for this are not entirely clear, since the estimates control for socioeconomic status, education and ease of access to healthcare, it is possible that the religion variables reflect different levels of confidence and trust in the healthcare system. This finding is not unique to this study. For instance, a study on maternal health-seeking behaviour based on the Ethiopian Demographic and Health Survey finds that Muslim women are less likely to seek delivery and postnatal care as compared with Orthodox women. ${ }^{23}$

There also appears to be considerable regional variation in healthcare-seeking behaviour, with households in Amhara being most likely to seek (higher level) care and those in SNNPR most likely to forego or delay seeking care. Since access to public health facilities in SNNPR seems to be at least at par or at times better as compared with other regions (see appendix 3 ), it is likely that the lower probability of using care in SNNPR may be due to the limited implementation of the fee waiver system, which since 2008 has attempted to increase access for the 'poorest of the poor' in this region as compared with Amhara and Oromiya regions. ${ }^{24}$

This paper adds to the literature on healthcareseeking behaviour and foregone care in Ethiopia using specific clinical vignettes, which avoids the problem of reporting bias due to the unperceived need for healthcare in low-income settings. ${ }^{11}$ While the use of such vignettes allows us to establish patterns of healthcareseeking behaviour across population groups that are not driven by differences in health status, there is the risk that the reported hypothetical healthcare-seeking behaviour does not match the actual healthcare-seeking behaviour. However, the overwhelming reliance on modern care found in the actual utilisation data (see appendix 4) does suggest that results from the vignettes analysis are able to capture preferences and are not merely a result of the lack of understanding of the survey instrument. The consistency between the hypothetical and actual behaviour reported is also supported by research carried out in other contexts. For instance, a study in the Netherlands shows a strong link between a reported tendency to consult a doctor and observed consultation rates. $^{25}$ Second, because the symptoms described in the vignettes are quite specific and severe, they might not pick up foregone care in relation to diseases that are more difficult to recognise or more chronic in nature. Third, while we have detailed information on individual and household (demand side) characteristics, we do not have information on healthcare supply, apart from the distance to healthcare facilities, which can be linked to the household data. 
Notwithstanding these limitations, based on the empirical evidence assembled in the paper we tend to conclude that the low utilisation rates in Ethiopia are unlikely to be linked to a lack of awareness of the symptoms of the most common diseases or a low-perceived need for healthcare. By reducing the cost of care, the scaling up of the recently introduced CBHI scheme may play an important role in enhancing access to healthcare. ${ }^{2627}$

\section{Author affiliations}

${ }^{1}$ Institute of Social Studies of Erasmus University Rotterdam, The Hague, The Netherlands

${ }^{2}$ Institute of Health Policy and Management of Erasmus University Rotterdam, Rotterdam, The Netherlands

${ }^{3}$ Poverty and Human Resource Research Department, Ethiopian Economic Association, Addis Ababa, Ethiopia

${ }^{4}$ Regional and Local Development Studies, Addis Ababa University, Addis Ababa, Ethiopia

${ }^{5}$ School of Foreign Service, Georgetown University, Doha, Qatar

Acknowledgements The authors would like to thank Getnet Mitikie, the Dean of the School of Public Health of Addis Ababa University, and Gabriela Flores for providing guidance on the development of the vignettes. Ellen Van de Poel's research is supported by the Netherlands Organisation for Scientific Research, Innovational Research Incentives Scheme, Veni project 451-11-031.

Contributors ADM designed the proposal, collected and cleaned the data and performed the analysis; EVP designed the proposal, prepared the questionnaire and performed the analysis; $Z Y$ performed data collection and cleaning; DA collected the data; GA designed the proposal and collected the data; ASB designed the proposal and commented on the analysis.

Funding The Netherlands Organisation for Scientific Research (grant number W07.45.103.00) covered the full cost of this study. The funding source had no role in the study design; in the collection, analysis and interpretation of the data; in the writing of the report; and in the decision to submit the paper for publication.

\section{Competing interests None.}

Ethics approval The study protocol was approved by the Ethics Committee of the International Institute of Social Studies of Erasmus University Rotterdam and informed consent was obtained from potential respondents prior to canvassing the survey. (approval reference: iss0001946).

Provenance and peer review Not commissioned; externally peer reviewed.

Data sharing statement No additional data are available.

Open Access This is an Open Access article distributed in accordance with the Creative Commons Attribution Non Commercial (CC BY-NC 3.0) license, which permits others to distribute, remix, adapt, build upon this work noncommercially, and license their derivative works on different terms, provided the original work is properly cited and the use is non-commercial. See: http:// creativecommons.org/licenses/by-nc/3.0/

\section{REFERENCES}

1. Balabanova D, McKee M, Mills A. Good health at low cost 25 years on: what makes a successful health system? London: London School of Hygiene \& Tropical Medicine, 2011:83-116.

2. Admassie A, Abebaw D, Woldemichael AD. Impact evaluation of the Ethiopian health services extension programme. J Dev Effect 2009;1:430-49.
3. Banteyerga $\mathrm{H}$. Ethiopia's health extension program: improving health through community involvement. MEDICC Review 2011;13:46-9.

4. Ethiopian Federal Ministry of Health. Planning and Programming Department. Health and health related indicators for 1992 EC (2000 GC). Addis Ababa: $\mathrm{FMoH}, 2000 ; 1-41$.

5. Ethiopian Federal Ministry of Health. Planning and Programming Department. Health and health related indicators for 1998 EC (2005/ 6 GC). Addis Ababa: $\mathrm{FMoH}, 2006 ; 1-62$.

6. Ethiopian Federal Ministry of Health. Planning and Programming Department. Health and health Related Indicators for 2003 EC (2011 GC). Addis Ababa: $\mathrm{FMoH}, 2011 ; 1-68$.

7. Mariam DH. Bridging the availability-utilization gap: the issue of quality in the provision of health care. Ethiop $J$ Health Dev 2011;25:1-2.

8. Demographic Health Survey. Measure DHS stat-compiler database. 2012. http://www.statcompiler.com

9. Mielck A, Kiess R, Knesebeck O, et al. Association between forgone care and household income among the elderly in five Western European countries-analyses based on survey data from the SHARE-study. BMC Health Serv Res 2009;1:52.

10. Schoen $C$, Dotty M. Inequities in access to medical care in 5 countries: findings from the 2001 Commonwealth Fund International Health Policy Survey. Health Policy 2004;67:309-22.

11. Barros AJD, Ransmans $\mathrm{C}$, Axelson $\mathrm{H}$, et al. Equity in maternal, newborn and child health interventions in Countdown to 2015: a retrospective review of survey data from 54 countries. Lancet 2012;239:1225-33

12. Bonfrer I, Van de Poel E, Grimm M, et al. Does health care utilization match needs in Africa? Challenging conventional needs measurement. Health Policy Plan 2013;2013:1-17.

13. World Health Organization. Reporting on the Ethiopian World Health Survey 2003. Geneva: WHO, 2005;1-85.

14. Central Statistical Authority of Ethiopia, ICF International. The 2011 Ethiopian demographic and health survey, Addis Ababa, Maryland: CSA and ICF, 2010;119-21.

15. Adamson J, Ben-Shlomo Y, Chaturvedi N, et al. Ethnicity, socio-economic position and gender-do they affect reported health —care seeking behaviour? Soc Sci Med 2003;57:895-904.

16. Chaturvedi N, Rai H, Ben-Shlomo Y. Lay diagnosis and health-care-seeking behaviour for chest pain in south Asians and Europeans. Lancet 1997;350:1578-83.

17. Chavez LM, Shrout PE, Alegría M, et al. Ethnic differences in perceived impairment and need for care. J Abnorm Child Psychol 2010;38:1165-77.

18. Frie KG, Eikemo TA, von dem Knesebeck O. Education and self-reported health care seeking behaviour in European welfare regimes: results from the European Social Survey. IJPHS 2010;55:217-20.

19. Benziger CP, Bernabe-Ortiz A, Miranda JJ, et al. Sex differences in health care-seeking behavior for Acute coronary syndrome in a low income country-Peru. Crit Pathw Cardiol 2011;10:99-103.

20. Population Census Commission. Summary and statistical report of the 2007 population and housing census: population size by age and sex. Addis Ababa: PCC, 2008;8-19.

21. World Health Organization. http://www.who.int/quantifying ehimpacts/national/countryprofile/ethiopia.pdf (accessed 3 Dec 2013).

22. UNDP. The 2013 human development report: human progress in a diverse world, New York: Palgrave Macmillan, 2013;140-55.

23. Ethiopian Society of Population Studies. Maternal health care seeking behaviour in Ethiopia: findings from EDHS 2005. Addis Ababa: ESPS, 2008:14-29.

24. USAID Ethiopia Health Sector Financing Reform: Midterm Project Evaluation. 2011. http://resources.ghtechproject.net.

25. Van der Meer J, Mackenbach J. Low education, high GP consultation rates: the effect of psychosocial factors. J Psychosom Res 1998;44:587-97.

26. Abt Associates Inc. Piloting community based health insurance in Ethiopia: health sector financing reform project. Addis Ababa: Abt Associates, 2009;1-23.

27. Ethiopian Federal Ministry of Health. Brief notes on the design of community based health insurance (CBHI), technical brief number 1. AddisAbaba: FMoH, 2007;1-15. 